\title{
5 COVID-19, gender, agriculture, and future research
}

\author{
Hannah Budge and Sally Shortall
}

\section{Care work and COVID-19: stories from farming communities in Scotland}

Coronavirus has undoubtedly impacted our global society in many unprecedented ways, affecting those from all walks of life. When we began to wonder about the consequences for women in the agriculture industry, we decided it would be best to hear from those who are involved in the sector. We conducted two focus groups with women in Scotland from a range of backgrounds who are connected to agriculture in various ways. Some are full-time farmers, some work part-time on the farm, some have senior positions off the farm but are involved in farming. We knew these women from previous research undertaken for the Scottish Government on women in agriculture in 2016 and 2017. Due to COVID-19, the focus groups were carried out by Zoom. Women from all over Scotland were involved in the Zooms, from the Scottish Borders with England right up to the Highlands. From the rich data, a number of themes emerged, and these are considered in turn. First, we examine what women described as the "reversal" of gender equality. Second, we consider the inequalities in domestic labor that became more pronounced during COVID-19. Finally, we look at the role women play as guardians of the mental well-being of their immediate and extended families. These discussions are followed by our reflections for future research.

\section{"Reversal" of gender equality}

All participants spoke of their frustrations of the immediate reversion to traditional gender roles in the household when lockdown began. One participant, a full-time farmer who suddenly found her husband and his employee working from home, commented that she felt there had been a regression 
in her stance as a woman, and that effectively all the progression which had occurred throughout her lifetime was being taken away.

I regressed to a woman's place, as in, you know, all the progress that I thought I had made in my life seemed to have slipped away.

This was due to being constantly expected to not just manage a farm, but to then take on the total management of the home with little help from partners and other household members. For instance, another commented that:

I was the responsible functioning adult that had to cook and do the shopping and lamb ewes and calve cows ... And they're like looking at me waiting to be fed.

Another woman, who had a senior position off the farm, also felt there had been a reversal in the level of equality she thought she had earned:

At home, I think people had got quite resilient because I'm not here that much. They had just gotten in their routine of just managing. Weirdly when I was here, they just expected me to just pick up and do everything. It felt like they reverted back to mum, mum will be in charge, mum will fix it.

In many respects, these quotes show the fragile nature of the gender equality that women have earned. Women have gained greater equality in the labor market. Yet this equality in paid employment, and increased participation in paid employment, has not translated into an equal division of domestic responsibilities. The European Institute for Gender Equality (2021) defines domestic responsibilities as "tasks performed inside a household in order to ensure that the basic needs of its members are met, such as cooking, cleaning, and taking care of children or older adults and other dependent family members." We are all aware that COVID-19 increased the amount of domestic responsibilities as adults worked from home, requiring additional meals, and children were home schooled. It is to this we now turn (Figure 5.1).

\section{COVID-19 and domestic responsibilities}

With one exception, all women reported that while there were an increased number of adults in the house, the responsibility for cooking and cleaning fell to them. One farmer with two additional men home working reported: 


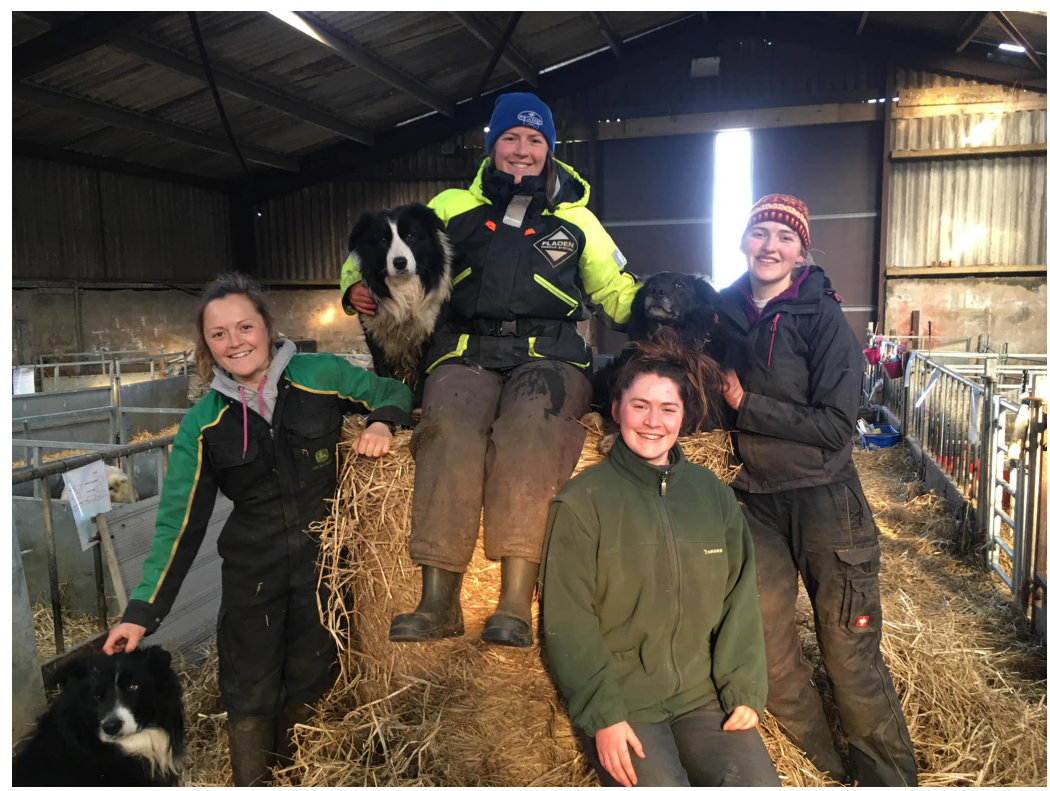

Figure 5.1 Farmers in Shetland take a break during lambing time (Hannah Budge).

I put a ready meal in the oven that nobody wanted to eat because they couldn't decide what they wanted to have, and then they wanted Yorkshire puddings with it. So in-between the ten minutes the Yorkshire puddings had to cook, I had to catch two ewes with mastitis. And they're looking at me waiting to be fed.

Prior to COVID-19 these men worked elsewhere and were responsible for their own lunch meals. Yet, the expectation that women provide the evening meal also spills into daytime even though women are also working full-time at home.

Another woman, working full-time off the farm with children, said:

He jumped in the machine and was off, I had to tell him to stop working because I can't do this. I can't be working my days and then have you coming home at half six, seven at night asking what's for tea and expecting me - and the kids coming through looking for tea as well.

This woman saw her husband as "jumping" into the tractor as a means of escape. He does contract work on other farms and she felt that this allows him to assume that all of the domestic responsibility falls to her 
because she is in the home, even though she is also working full-time and long days.

A woman who primarily does office work on the farm as well as parttime work in some organizations reported:

I am going to sound like a broken record, obviously having to manage the childcare and home schooling, juggling that and then if the other person is committed to sort of twelve hours day, whether that be lambing, calving, sowing, whatever, just trying to juggle that, I think, puts extra pressure on the family and extra pressure I guess on relationships and everything else.

The key message is that when both partners are working full-time, domestic labor remains predominantly or solely women's work. This remained the case even when this work increased exponentially during COVID-19, underscoring the division of domestic labor as central to equality and well-being. Interestingly, we did find one exception. This was in an all-female household, where one woman farms full-time, her sister farms part-time, and now another sister and the mother are working from home during COVID-19. In this case, the women farmers were not expected to prepare meals. Rather the other two women working from home assumed this responsibility:

Sometimes I will do it, sometimes it might be my Mum she might make it the night before. But it definitely wouldn't be Joan or Lori who are working on the farm.

It is interesting that here, where the non-farming household members are women, the women farmers are not expected to cook, which is different from previous participant's situation. It underlines the gendered understanding of expectations around domestic duties; women share domestic labor.

In all cases where women had children, they shouldered the weight of home schooling. There have been many newspaper reports regarding this issue; throughout COVID-19 it has consistently been the woman in the parenting partnership who is expected to take on the role of teacher, organize study time and when children do their homework. This was reflected by the women interviewed:

It's the mum guilt. I feel that the home schooling landed on my plate to deal with. It didn't ever cross Ben's mind to enforce it. I felt it was me that had to engage with the school and find out what was happening. It was the whole guilt and it felt like I was still the one having to like to 
make sure they still did physical activity like going for bike rides, and those kinds of things.

Women spoke about the additional burden of home schooling repeatedly, and also about feeling guilty that they were not achieving what they felt they ought to be. They worried their children were falling behind with their studies. In another case, one woman spoke about feeling she was failing because she compared herself to other mothers when her children reported progress to school and could see what other children had achieved:

But that's all very well because their friends maybe have mums who are at home, or are furloughed, ${ }^{1}$ who have got time and I think you get a bit of anxiety with that looking at what everybody is posting each day and interacting with the teachers. Whereas my pair are like ... they've got so far behind that they're just not bothering, and it maybe slightly worries them a wee bit. It's not been great and I have felt very, very guilty not having time to sit with them.

Women presume that other women in families will carry the home-schooling responsibilities during COVID-19. These women judge themselves to have failed compared to other mothers who may have more time to invest in the process. Without exception the women in our focus groups with children shouldered this responsibility, even, in one case, involving three young children of different ages, and thus with different home-schooling needs (Figure 5.2).

\section{Guardians of mental well-being during COVID-19}

The focus group participants spoke about their different mental health responsibilities related to COVID-19. One woman involved with a mental health charity recounted that the number of women phoning for support on behalf of a male relative, and also wishing to know how they could best support them, had increased dramatically since the start of their pandemic. Others spoke of how women had felt they were responsible for the entire family:

cooking, shopping, meds for elderly family, keeping the kids going, women are feeling that they're the ones responsible for keeping everything going and keeping everyone happy. Umm and that's a lot of pressure.

The pandemic has increased "mental" labor. There is providing support, but also ensuring routines, so that children maintain their mental well-being. Women reported this as exhausting: 


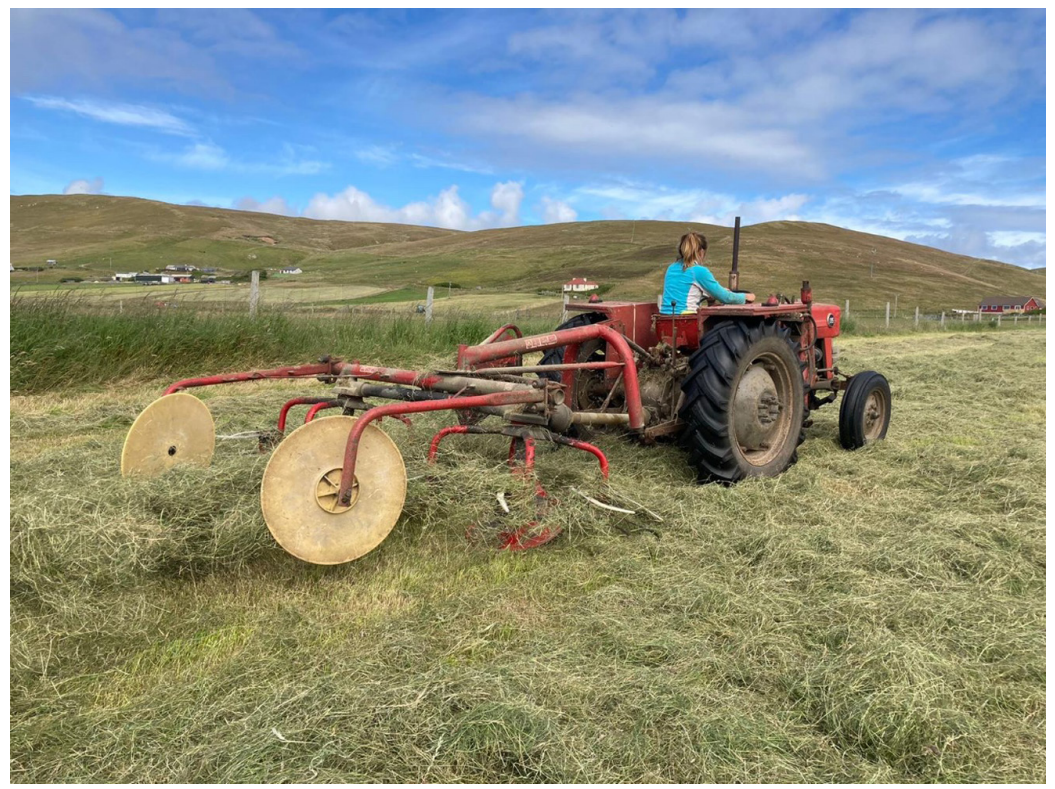

Figure 5.2 Farmer using machinery to ready the hay (Hannah Budge).

Mentally, my biggest issue has been headspace and it's going to sound, and I don't mean to sound kind of poor me, the cooking I don't mind but the having to make a decision every single day for what we are eating, what we are buying at the shops, what time the kids are getting out of bed, what we do during the day is overwhelming, on top of work.

Much of this mental labor is invisible. These are responsibilities that women largely do unspoken, in their heads. COVID-19 has increased the amount of this labor. As mentioned, the concern of the emotional wellbeing of others in the household falls again on the women in the household, one participant said:

So yeah, so they are needing a hell of a lot of emotional support just now, and unsurprisingly that falls to me.

Mental health support also extends to the elderly and women spoke about how they also assumed responsibility for that. One woman said: 
We are picking up the traditional role and caring of the elderly very much features in that. You want to look out for their mental health, I've got an eighty-year-old mother two miles up the road and the issue of isolation is very real.

While women spoke of their concerns about their children falling behind with schoolwork, they also talked about how their children's mental health and keeping them mentally well during the pandemic was a priority. They saw it as more important than schooling. This is clear from the following discussion in one of the focus groups:

Mary: People like me, people who are working on the farm that it's the home schooling that's gone. And we've had to say we cannot home school the kids. The kids are out with us, I actually think the kids, the kids look so bloody happy. They look happy, they look healthy, the do look really happy because they are together. You know we are just going to focus on the immediate, focus on the family, focus on matters for the next few months.

Harriet: My sister is a teacher, and their main thing is that they don't worry. About the education part of it, as long as children are happy that's the main thing, so you are right Mary.

Martha: We were very lucky in that Emma's teacher is very, very much your sister's thinking, Harriet, that you know, family and kind of being secure takes precedence.

The pandemic has highlighted the amount of mental labor that women do in the family, a form of labor we don't often think about, but which increased considerably during the pandemic. Women have increased the mental planning to do around more meals to be prepared, organizing daily routines for the family, organizing home schooling and combining this with their own work commitments. In addition, their role in ensuring the well-being of other family members is evident, ensuring they have support, company, and routines. This covers all generations, their spouses, children, and elderly parents. Women are ringing mental well-being helplines on behalf of their husbands, supporting children through home schooling, and missing friends, and ensuring elderly relatives stay connected and are not isolated. Particular issues arise for women caring for children on farms during the pandemic. The farm is a workplace as well as a home, and, as previous research has shown, it is a dangerous work place leading to increased stress of ensuring children are safely at play. 


\section{Hannah Budge and Sally Shortall}

\section{Reflections and future research}

Disasters have often advanced women's equality. Both World Wars led to the increased participation of women in the labor market and undertaking farm work, which increased understanding of women's ability to contribute to productivity, to lead, and to make decisions. At this point in the pandemic, it seems to highlight the precarious nature of the equality women have achieved in the labor market. The focus has been on equality in the labor market and less on equality in the division of domestic labor. In terms of farming, we have tended to focus on how women secure entry to a masculine profession and how they are treated once they become farmers. In the future we will not just look at women's success in the industry as a measure of equality, we will also pay closer attention to the division of responsibilities within the home unit. Who has responsibility for what? We will also be mindful of the hidden mental domestic responsibilities; who organizes the day and who writes the grocery list are chores that often go unnoticed. Mental domestic labor is an area of research that requires much greater study. The most equal situation in the focus group was the farm where there are multiple women, some of whom do not work on the farm. We will question going forward whether, in agriculture, same-sex relationships and same-sex households have a fairer distribution of domestic labor and tasks.

\section{Note}

1 In the UK, the "furlough" scheme paid some workers unable to go to work while they were at home. It was a more generous payment than basic social security.

\section{Reference}

European Institute for Gender Equality. (2021) Domestic responsibilities. Available at https://eige.europa.eu/thesaurus/terms/1088 (Accessed 5 March, 2021). 